\title{
Modal Analysis of Frame Structure Teaching Building
}

\author{
Ji Dongyu \\ Hunan Urban Construction College \\ Xiangtan, China \\ hnjdy@126.com
}

\begin{abstract}
In order to have a clear understanding for frame structure's vibration modal, and improving the structure's dynamic characteristics. This paper adopts finite element method to simulate and calculate frame structure teaching building, and gets natural frequency and vibration mode of frame structure teaching building, and analyses and explain calculation results. Analysis results show that the frame structure buildings is economic and reasonable, can satisfy the engineering requirement. The results showed that, the first and second order vibration mode of teaching building structure is translational vibration mode, and the upper vibration mode is main, the dynamic characteristics of teaching building structure are more complicated, the vibration modal of teaching building structure are mainly translational in the process of vibration, teaching building structure's transverse stiffness is minimum, the longitudinal stiffness is more smaller, The vertical stiffness is maximum.
\end{abstract}

Keywords-Frame structure; Teaching building; Modal analysis; Finite element method; Vibration frequency.

\section{INTRODUCTION}

With the rapid development of construction industry in our country, reinforced concrete frame structure has been widely used[1]. In order to accurately calculate natural frequency and vibration mode of reinforced concrete frame structure and provide a solid theoretical basis for structure design, international scholars carried on the thorough research,and the birth of the finite element method provides an effective way to solve this problem[2-3].

\author{
Li Lamei \\ North China University of Water Resources and Electric \\ Power \\ Zhengzhou, China \\ 834178464@qq.com
}

II. SUMMARY

The teaching building is reinforced concrete frame structure system, this building is 6 floors, story height of the first floor is $7 \mathrm{~m}$, story height of other floor is $4.2 \mathrm{~m}$. Construction area is $8425 \mathrm{~m}^{2}$, the building is rectangle in plane view. Foundation adopts sand gravel, thickness is 2 $\mathrm{m}[4]$.

\section{CAlCUlation Model}

\section{A Model Parameters.}

The concrete strength grade of frame structure teaching building is $\mathrm{C} 40$, elastic modulus of concrete is $32.5 \mathrm{GPa}$ [5-6], poisson's ratio of concrete is 0.2 , density is $2500 \mathrm{~kg} / \mathrm{m}^{3}$. Elastic modulus of foundation is $0.261 \mathrm{GPa}$, poisson's ratio is 0.27 , density is $2660 \mathrm{~kg} / \mathrm{m}^{3}$.

\section{B Finite element model}

In the finite element calculation model of frame structure teaching building, beams and columns adopt Beam188 element, floor adopts Shell63 element, foundation soil adopts Solid45 element[7-8].

In order to make real simulation of frame structure teaching building structure'force, the foundation size according to Saint-Venant's Principle[9]. Length of foundation is $100 \mathrm{~m}$, width of foundation is $30 \mathrm{~m}$, depth of foundation is $2 \mathrm{~m}$. In the finite element calculation model of frame structure teaching building structure, Y direction is height direction, $\mathrm{Z}$ direction and $\mathrm{X}$ direction is horizontal direction[10], finite element calculation model shows in the Fig .1.

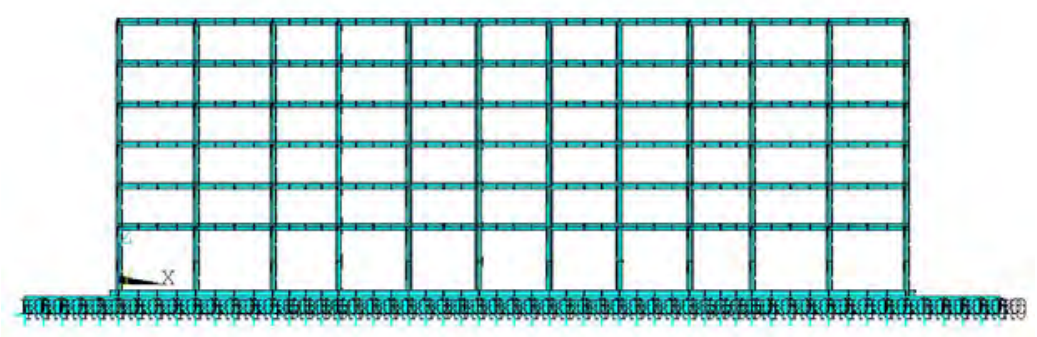

Figure 1. Finite element calculation model of frame structure teaching building structure

\section{ANALYSIS OF CALCULATION RESULTS}

Modal analysis is the study of structural dynamic characteristics, to calculate natural frequency and vibration mode. Natural frequency can represent the overall stiffness, low natural frequency represents structure stiffness is small and structure is very soft, high natural frequency represents structure stiffness is large and structure is very hard. From modal modal, we can know the deformation trend of the structure under a certain natural frequency. If structure need to be strengthened, we can strengthen the weaker part firstiy. This paper calculates and analyses dynamic characteristics of frame 
structure teaching building structure, obtain the first fourteen vibration modes and frequencies of this structure.

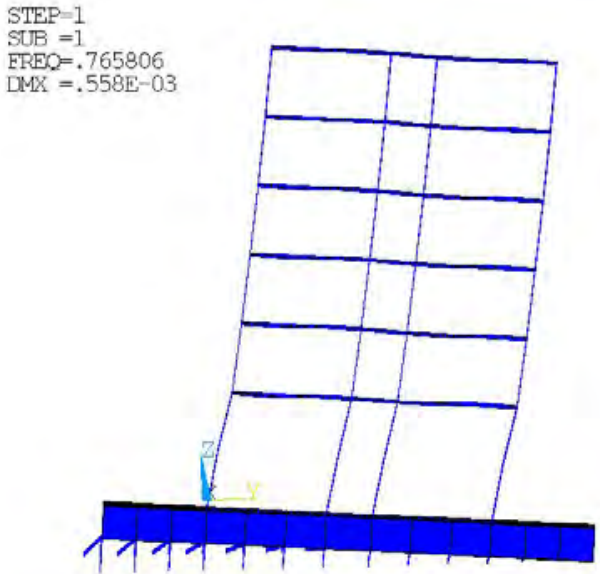

Figure 2. The first order vibration mode

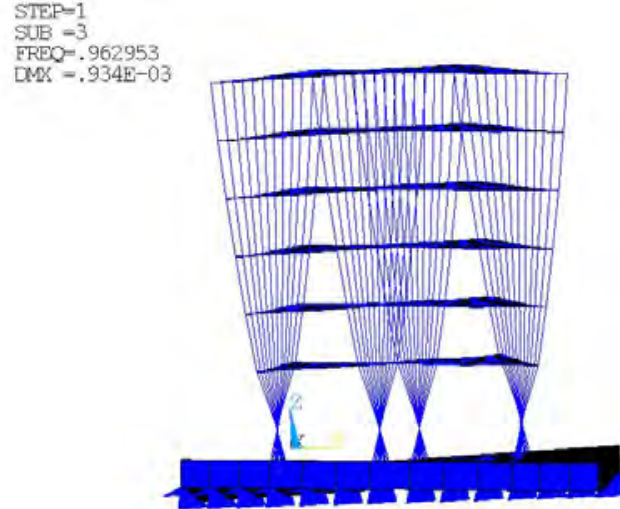

Figure 4. The third order vibration mode

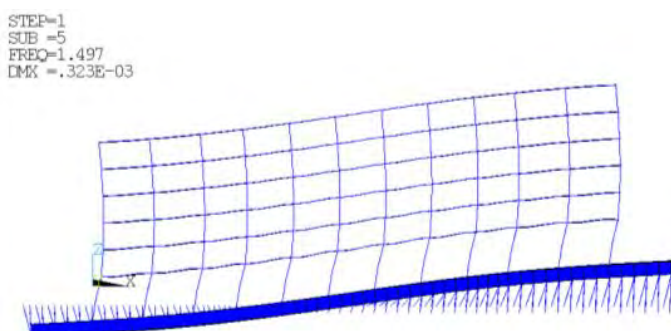

Figure 6 . The fifth order vibration mode

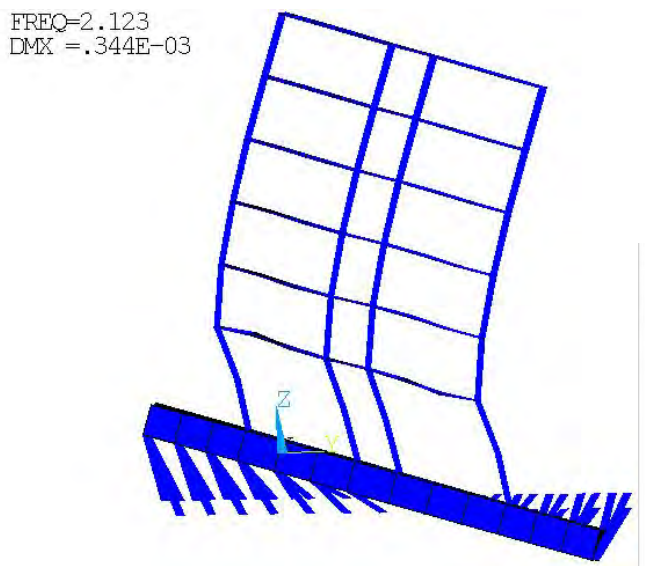

Figure 8 . The seventh order vibration mode
Each order vibration mode of frame structure teaching building structure shows in the Fig .2 to Fig .15.

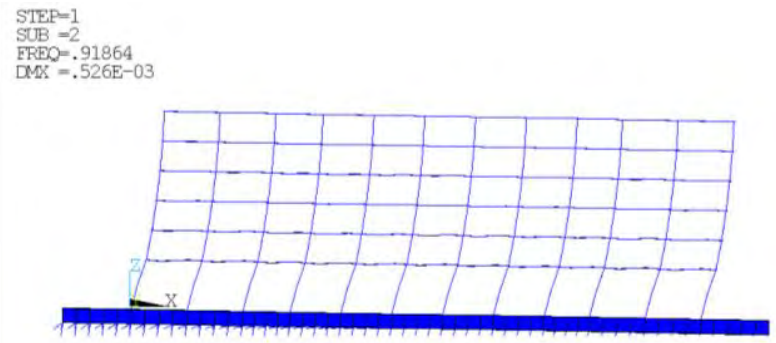

Figure 3. The second order vibration mode

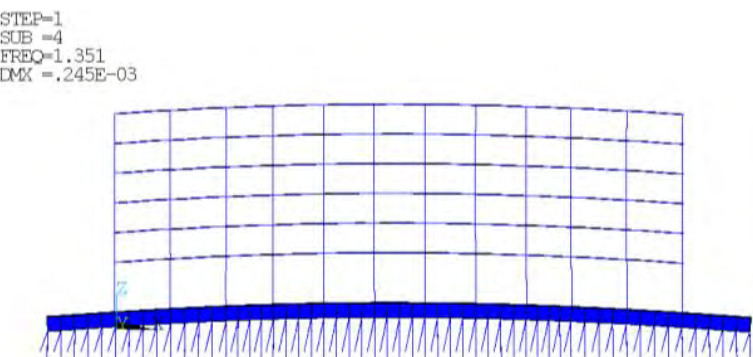

Figure 5. The fourth order vibration mode

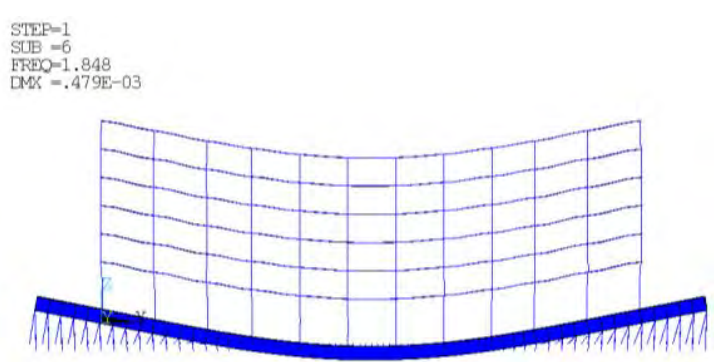

Figure 7. The sixth order vibration mode

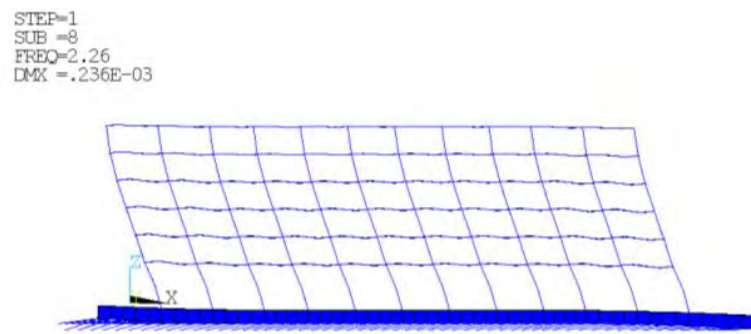

Figure 9. The eighth order vibration mode 


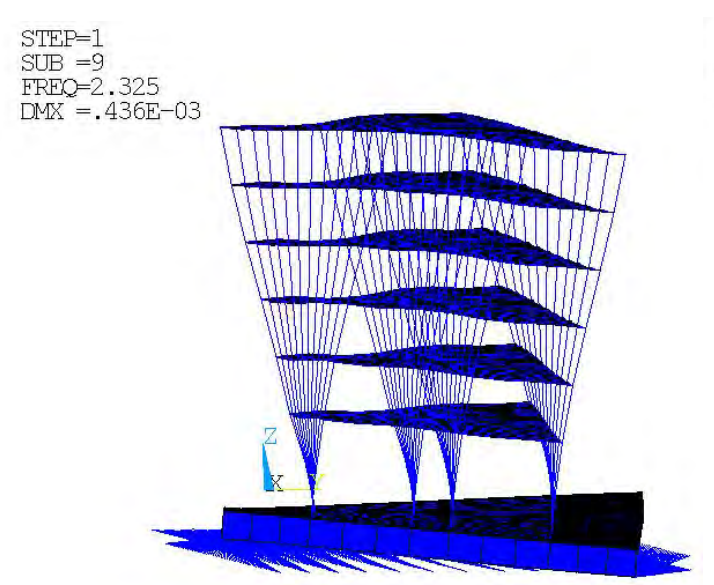

Figure 10. The ninth order vibration mode

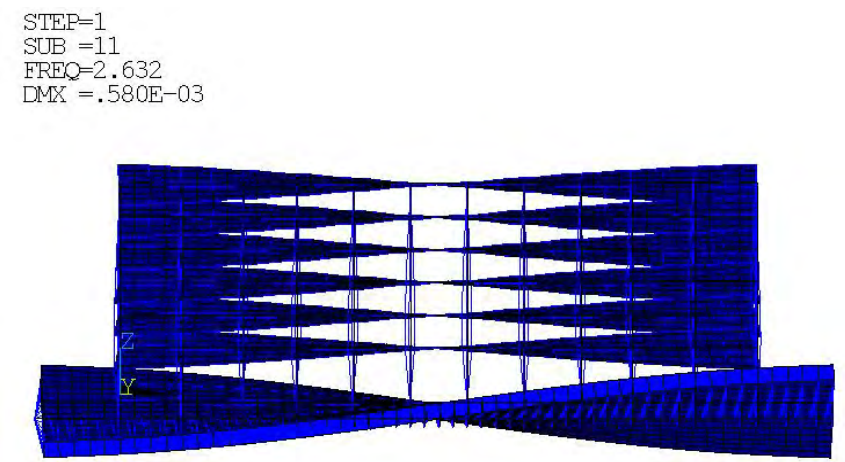

Figure 12. The eleventh order vibration mode

$\mathrm{STEP}=1$

$\mathrm{FREQ}=3.474$

$\mathrm{DMX}=.565 \mathrm{E}-03$

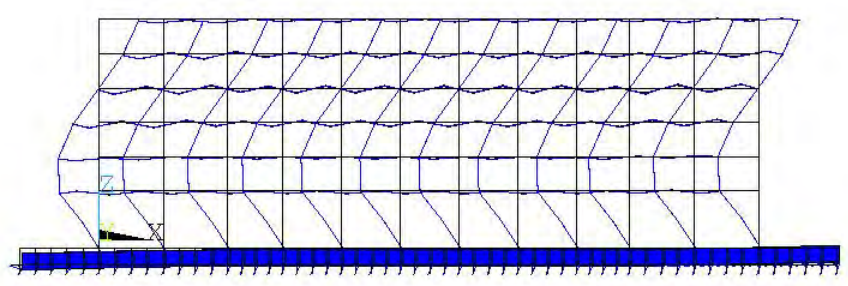

Figure 14. The thirteenth order vibration mode

As can be seen from the Fig .2 to the Fig .15, the difference value of the first three vibration modes and frequencies of frame structure teaching building structure is very small, the first and the second order vibration mode of high-rise connected structure are translational vibration mode, the third order vibration mode is torsional vibration mode, the fourth order, fifth order, sixth order vibration mode are vertical vibration mode, the seventh order, eighth order, ninth order, tenth order, eleventh order,

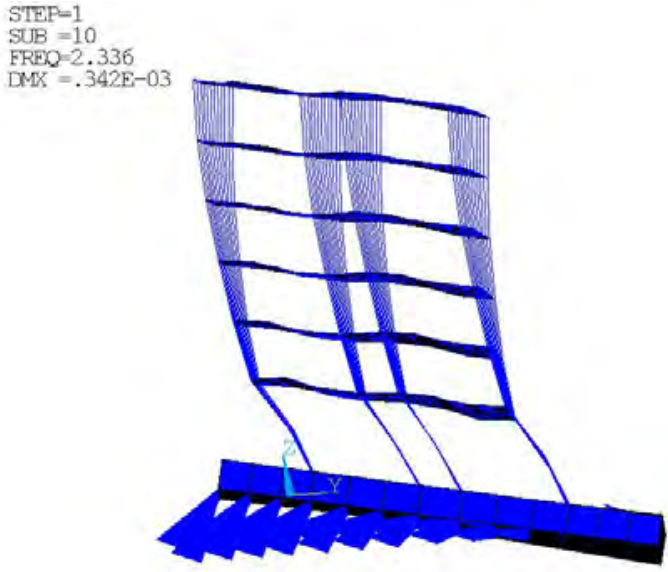

Figure 11. The tenth order vibration mode
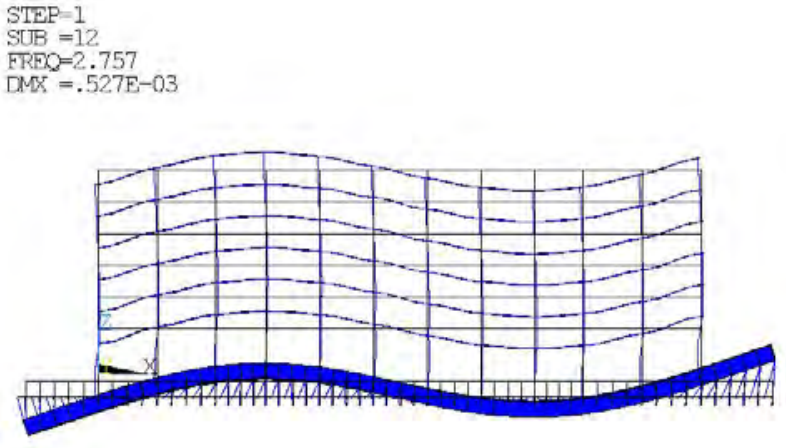

Figure 13. The twelfth order vibration mode

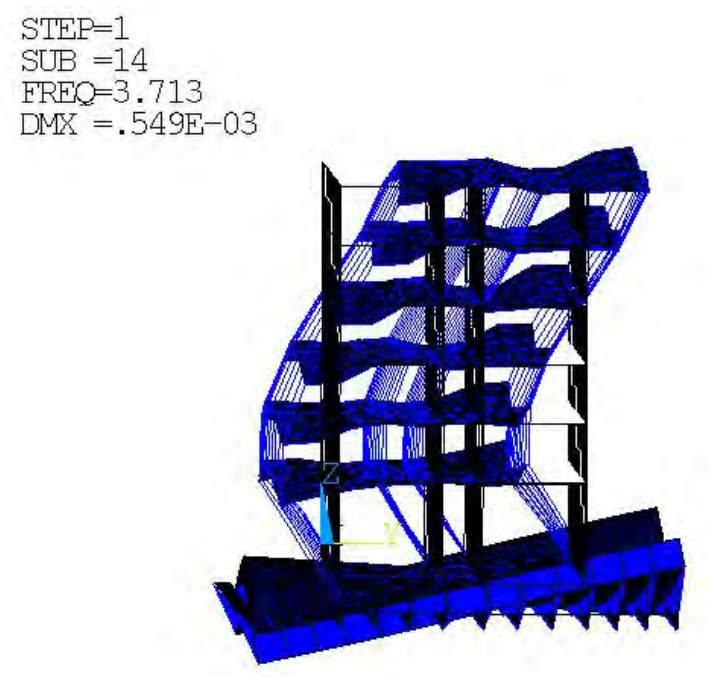

Figure 15. The fourteenth order vibration mode

twelfth order, thirteenth order, fourteenth order vibration mode are torsional vibration mode.

With order increasing, transverse vibration occurs first, then longitudinal vibration occurs, finally vrtical vibration occurs. Because vibration often happen first in the smaller stiffness part of frame structure teaching building structure, therefore, transverse stiffness of frame structure teaching building structure is minimum, longitudinal stiffness takes second place, vertical stiffness is maximum. The first and 
the second order vibration mode of frame structure teaching building structure are all translational vibration mode,the vibration mode of upper structure is the main vibration mode, shows that integral stiffness of lower structure is bigger.

\section{CONCLUSION}

In conclusion,through the dynamic characteristic analysis of frame structure teaching building structure, we can obtain the following conclusion:

(1) The dynamic characteristics of frame structure teaching building structure is more complex.

(2) The first and the second order vibration mode of frame structure teaching building structure are given priority to translational vibration mode.

(3) Transverse stiffness of frame structure teaching building structure is minimum, longitudinal stiffness takes second place, vertical stiffness is maximum.

\section{REFERENCE}

[1] Tung-Yueh Wu,Wen-Chang Tsai,Jyh-Jone Lee et al. Dynamic elastic-plastic and large deflection analyses of frame structures using motion analysis of structures [J]. Thin-Walled structures,2009,47(11): 2036-2045.
[2] Wentong Liu. Development and application of the structural system with special-shaped columns [J]. Jiangsu Construction,2008(1):36-37.

[3] Akanshu Sharma,G.R. Reddy,K.K. Vaze et al. Shake table tests on a non-seismically detailed RC frame structure [J]. Structural engineering and mechanics,2012,41(1):1-24.

[4] Zhang, Jing. Optimization of MAC Frame Structure for Opportunistic Spectrum Access [J]. IEEE transactions on wireless communications,2012,11(6):2036-2045.

[5] Junfang Wang, Min Wang, Fengcheng Zhan. The internal force calculation of the special-shaped column frame structure under horizontal loads [J]. Sichuan Building Science, 2007(6):38-40.

[6] Alessandra Fiore,Adriana Netti,Pietro Monaco et al. The influence of masonry infill on the seismic behaviour of RC frame buildings [J]. Engineering structures,2012,44(Nov.):133-145.

[7] Xucheng Wang. Finite Element Method [M]. Tsinghua University Press, 2003.

[8] Thang Nguyen Dao,John W. van de Lindt. Loss Analysis for Wood Frame Buildings during Hurricanes. I: Structure and Hazard Modeling [J]. Journal of Performance of Constructed Facilities,2012,26(6):729-738.

[9] Jianjing Jiang, Xinzheng Lu, Lieping Ye. Finite Element Analysis of Concrete Structures [M]. Tsinghua University Press, 2004.

[10] G. A. Lesieutre,J. A. Browne,M. I. Frecker et al. Scaling of Performance, Weight, and Actuation of a 2-D Compliant Cellular Frame Structure for a Morphing Wing [J]. Journal of intelligent material systems and structures,2011,22(10):979-986. 